\title{
Under Some Delusion: Considerations On The Limits of E-Democracy
}

\author{
Neil Collins ${ }^{1}$, Patrick Butler² \\ 'Department of Government, University College Cork, Ireland \\ ${ }^{2}$ School of Business Studies, Trinity College Dublin, Ireland
}

\begin{abstract}
The potential for electronic access to information and channels of participation is fraught with danger for democracy. For political and public sector interests to follow slavishly the commercial pioneers is highly questionable, and probably perilous. The inherently conflictual nature of both government and democracy demands attention to the institutions and patterns of representative democracy. Consideration in the first instance of the peculiar aspects of public sector products, organisations and marketplaces would bring a contextual sensitivity to the project, thereby improving design and application of e-based solutions. More attention should be paid to the mechanisms of representative democracy so that they can be incorporated into e-systems rather than clash with them.
\end{abstract}

\section{E-GOVERNMENT AND E-DEMOCRACY}

The people never give up their liberties but under some delusion. (Edmund Burke, Speech at County Meeting, Buckinghamshire, England, 1784)

E-Government and e-democracy have been discussed as if they could be usefully differentiated. The former is about service delivery, especially where information and its availability are key, and the latter involves the use of the new technology to facilitate widespread, immediate and efficient participation. This distinction represents the most recent manifestation of a recurring search for a distinction between public administration and politics i.e. between the neutral application of management techniques, and politically charged expressions of value. The central contention of this paper is that the separation of these concepts conveys a false sense that they may be examined and developed in isolation. Information, however 
transmitted, is seldom neutral - even more so when it concerns access to, distribution of, or accountability for public sector services. Hence, the same caution that characterises today's liberal democracy should guide how e-systems deal with the demands of the public.

In the foregoing quotation, the Irish philosopher Edmund Burke was commenting at a time when popular views were being expressed in the United Kingdom, France, and elsewhere in Europe via the large scale, popular, participative method of mob rule. Liberal democracies have since developed ways of facilitating popular participation with political accountability, responsibility and transparency through the institutions of representative democracy. The direct democracy commonly suggested in the e-government and e-democracy debate is potentially dangerous and naïve. It implies that what is technically possible is politically or democratically desirable.

As direct democracy takes root, the Americans voter will become more involved and active. We don't have to wait anymore for the next election to express our views while Congress makes decisions for us. We don't have to wait for a call from a pollster to speak our piece. We are going to take to the Internet and tell our representatives what to do whenever we damn well feel like it (Morris 2000; ixia).

Such assertions are not dissimilar to those that provoked Burke's views regarding the rise of demagogues and popular movements in the late eighteenth century. It is notable, of course, that democracy did not always have positive connotations. For most "thinking" people up until the twentieth century, democracy was to be treated with caution, since it meant rule by the common masses. We have moved on from Burke but his advice may still be valuable.

\section{POLITICAL DISCOURSE}

The dominant neo-liberal paradigm of current political discourse is based on an analogy with the free market. Deregulation, customers, clients, partnerships and so on. are the concepts that inform new public management. It is apposite, therefore, that the notion that the market will readily adopt a so-called technology-push model in every case has been seen to be severely limiting even in purely commercial terms. The recent situation regarding the relative failure of business-to-business (B2B) exchanges is a case in point. The hyperbole surrounding the potential of such activity, based on the lowest cost-best price model, was seen to offer a false hope. This is a market that never reached anything near the expectations promoted by many in the field. While there are multiple and complex explanations for this, there 
is a consensus that just because the technology was available to revise and improve the way firms organised their procurement processes, firms did not necessarily adopt what appeared to be the "best" model (see Kaplan and Sawhney 2000, Wise and Morrisson 2000). There are many more factors involved in the total transaction cost explanation than simply price. Indeed, one of the features of industrial marketing in the past decade has been the shift away from a purely price-based model of competition, and toward a long-term, interactive relationship orientation (Webster 1992, Ford 1990). The market efficiencies assumed in the electronic business environment do not always provide the best overall model of exchange. In the political "marketplace", similarly, the most technologically efficient approach will not necessarily provide for the most appropriate solution. Both e-government and edemocracy may well accentuate the cumulative inequalities that mark all liberal democracies in terms of access to public resources.

Politics involves translating electors' preferences into political action in the form of public services. The stable society is one where people feel that the pattern of service delivery is fair and equitable, as well as efficient. For most people, the pattern of the consumption of public services is their sense of democracy. Many of the descriptions of electronic government address this service delivery dimension. They neglect, however, fundamental questions of democratic principles and processes. As Steven Clift observed at the UK House of Commons Public Administration Select Committee, "the Minnesota E-democracy project, widely regarded as a beacon of best practice, suggested that the main value of e-democracy is not in the executive (government delivery) wing of governance, but the legislative wing where links between legislators and the citizens" (http://www.parliament.thestationeryoffice.co.uk/pa/cm1999).

Citizens give their opinions, whether electronically or otherwise, to affect policy outcomes. Sometimes the results may be declaratory, but more often the intention is a change in the pattern of service provision or financial burden. The emphasis here, therefore, is the attempt to broaden the question of applying ICT to governing. In this volume, Gronlund makes the specific case for including existing representative systems of democracy that already inform and coordinate societal planning, governance and organisation in civil society. This is an important perspective, particularly in the context of continually evolving e-type models in all areas of the social sciences - including, importantly, economics and management. It is by no means clear that electronic brokerage effects and electronic integration effects have been fully understood, for instance. Given the disastrous market assessments within the "dotcom" sectors, for political and public sector interests to follow slavishly the commercial pioneers is highly questionable and probably perilous. 


\section{PUBLIC OPINION AND PUBLIC POLICY}

Existing representative systems of democracy have built up "checks and balances" between popular opinion and the delivery of public services. In a democracy, every citizen is assumed to have views of equal value on a wide range of public issues. The number of potential combinations of opinion, therefore, is vast. The political system deals with the divergent tasks of facilitating the articulation of views while aggregating them into manageable combinations as expressed in party manifestos, government policy statements and the like. Ultimately, for any one policy issue, governments, parliaments and other public agencies must be presented with very few options for decision. By this we mean that representative institutions play a role in drawing together and assessing ideas in the public domain. These "filtering mechanisms" have acted to dampen the impact of changes in public opinion on policy. New proposals relating to e-democracy and e-government tend to suggest more direct links between public opinion and government policy, inherently implying that these intermediating institutions may be bypassed.

When will voters be consulted on important issues? Whenever they want to be. Anytime enough Internet users want to have a referendum they will simply have one. There will likely be hundreds of referendums each year. (Morris 2000:33)

It seems that commercial models that promote a narrow definition of political reality in which opinions on policy issues are the equivalent of consumer preferences overly influence the debate on e-democracy. There is also a critical danger that the American political system of weak legislative parties and fractured party competition will be assumed as the rule rather than the exception. In most liberal democracies, disciplined and ideologically differentiated parties provide welldefined options across a wide range of policy areas. The analogy of a market constantly being guided towards some optimal equilibrium by the "invisible hand" of competing consumer preferences is too overdrawn to be helpful.

The issues raised by the evolution of e-government and e-democracy are broad. This paper, therefore, concentrates on a particularly neglected aspect of the debate. The argument here is twofold: e-based models that offer more efficient solutions to governing may be too simplistic to accommodate the complexities of public sector management and service delivery; and, those political and public service complexities must be recognised and addressed specifically to evaluate the appropriateness or otherwise of electronic interventions or means of conducting business in these contexts. 


\section{THE NEW PUBLIC SECTOR}

With the recent managerialist public sector reforms in the western democracies, the primary focus has been on the lessons from the private sector. The demise of the venerable term "public administration" and the ascendancy of "public management" is evidence of this. If we are to make progress by incorporating electronic platforms and delivery mechanisms in the public sector, we must recognise the changing relationship between the state and the citizen. Hence, we are obliged to be clear about how we conceptualise the public sector.

The literature on public management, including healthcare, education, leisure and tourism is diverse and fragmented. There is no generally accepted model or framework that, by addressing the public sector context in its entirety, provides a guide to practitioners. No consensus exists about what the public sector and its 'products' are. There are no inherent properties of goods and services that make them 'naturally' public services. As Lane (1993) puts it: "There is no single way to make the private-public distinction" (p45). In the same way that management analysts and practitioners must grasp the essential issues in the financial services, business-to-business, high technology and fast-moving consumer goods industries, the public sector must be understood in order to adapt management frameworks, tools and techniques. This contextual analysis must certainly precede the added complications of considering and developing electronic communications and delivery mechanisms. The approach taken here is to delineate those distinctive factors in the public sector context that have implications for strategy and management.

While the literature on public management is extensive, we draw attention to three distinctive aspects of public services, an understanding of which give support to the application of electronically-based management approaches. These areas are:

- the public service product;

- the public service organisation; and,

- the public service marketplace.

\subsection{Public Sector Products and the e Debate}

There are many distinctive features of public sector products. While governments provide physical infrastructure like roads, hospitals and housing, in the main the provision is service-based. Services have their own kinds of delivery models, the field is well established in the literature, and specific public sector models have been developed (Butler and Collins 1995). It is notable that public services also include constraints on behaviour, such as rules and regulations restricting activities, and duties that require adherence to particular behaviours, such as filling in census forms, and, in some states, voting in elections. Such private constraint is seen as the 'price' of public benefit; there exists an acceptance on the part of citizens in the 
democratic order of the need to be constrained. This acceptance, is, however, dependent on the assumption that due process has been followed, i.e. that the constraints have been legitimised according to the norms of the political system. E-government will also have to demonstrate that it fulfils the criteria of liberal democracy.

Perhaps the most distinctive aspect of concern to this discussion is that public services often contain elements of what economists understand as 'public goods' (Page 1983). Specifically, these are consumed jointly i.e. consumers are not rivals; and, one cannot exclude from the consumption benefits those who do not pay. The providers of public services face the classic 'free rider' dilemma. For example, the streetlights shine on everyone whether or not they contribute to the cost through taxation; the village green is owned by all. There is a sense of collective obligation in the provision of resources for public goods. It is generally accepted that individualistic self-interest can militate against the general good in the allocation of certain products. The implications for managing public goods include the recognition of the imperfect link between provision and payment.

For the development of e-government, this question of public goods demands specialist attention. It may be argued that the examples noted above are, by definition, local phenomena. As such, if there is any element of free-riding, it is most likely to be by fellow-citizens. By complete contrast, the provision of a range of public services in an e mode - over the Internet, for instance - allows free riding on a global scale. That is, publicly available products and services may be accessible to people from any location. Within the nation state, even public goods are the responsibility of identifiable individuals and the democratic system can be held accountable. Both the principal and agent are known. With e-delivery, on the other hand, this link can be far more tenuous.

Addressing such issues, particularly in the area of information provision, might require some agreements between nations on the division of labour and perhaps proportional contributions to services online. Unless the problem is addressed, there would be no reason for public bodies to innovate and develop new material. This is akin to the threat to intellectual property rights of mass scale digital copying of copyrighted material. For instance, the music industry is especially vulnerable in this regard, and is currently waging defensive battles on technological, political and legal fronts. The music industry is perceived by observers to be at the cutting edge of such monumental structural change, and development are being watched very closely by others who anticipate similar issues in their own field.

The information culture of the Web community is very different to the "Old Economy" view. It would be held that, in a sharing, win-win environment, there is no economic value in scarcity of information, except in exceptional and specific situations. The knowledge society approach is that information wants to be free and should be accommodated.

Where access to information must be constrained, technological solutions will be developed. So, for instance, coded access based on secure technologies should 
enable people and institutions to resolve matters associated with public good characteristics. These, however, are peculiar to the public sector, and demand examination to a degree not usually considered in private sector initiatives.

\subsection{Public Sector Organisations and the eDebate}

Among the primary characteristics of most public sector organisations are the increasing adoption of managerialist perspectives and techniques, the not-for-profit ethos and political accountability. Professional management, explicit standards of performance, private sector styles of practice and parsimony in resource use are all features of the public sector today. While many products have not changed fundamentally, there have been radical changes in the organisation for their delivery. Public sector organisations also display many of the characteristics associated with those in the private not-for-profit sector. Among charities, trusts, human rights and medical organisations, the primary goal of the organisation is not profit. Although trading activities may well produce a profit, that is generally referred to as "surplus".

The political accountability of public sector organisations has special implications for how they might engage with electronic forms of information, communication and service delivery. The actions of public service organisations have the potential of being scrutinised by the public or their political representatives in ways that do not exist in the private commercial world. Even relatively new organisational arrangements, such as contracting out, executive agencies and publicprivate partnerships, have not generally severed this political link. As such, relatively minor errors risk becoming political scandals. It follows that organisations in the public sector are cautious, rule-bound and relatively inflexible. This, of course, is in contrast to the culture of openness, sharing and experiment among individuals and entities in the virtual world.

By way of an example of the difficulties to which this political accountability gives rise, the case of the French Government versus Yahoo!.com is illustrative. In this situation, the Government sought to control public access to information regarding Nazi memorabilia on the World Wide Web. The tradition of political institutions is that they provide a form of control in the interests of the community; the e-environment challenges and undermines this by its avowed openness. Accountability is important in many domains, but public sector organisational accountability is rife with sensitivities, principle and community acceptance. Where electronic communication issues enter the arena, the matters are exacerbated.

Further, to questions regarding public organisation characteristics, the structuring of political, or public sector, organisations is traditionally functional. That is, government departments organise around functions such as finance, security, welfare and education. That makes perfect organisational sense from the supplier's perspective. However, the consuming citizen might not understand that form of organisation. One of the lessons of e-business development is the successful 
application of metamarket theory - a market of markets. That is, while business firms tend to think in terms of products and industry sectors, consumers perceive their worlds in terms of activities. So, for instance, the human activity that draws together businesses in such ostensibly different industries as flowers, hotels, clothing, photography, music and religious services is the wedding. The Web offers a highly efficient medium for aggregating such streams. It is an aggregator that enables the convergence of services.

For government, and, critically, for e-democracy, there is significant merit in exploring how citizens perceive the overlap and separation of public services, and of their entitlements and duties. There may be particular welfare effects in presenting the approach that the government is integrated, united and working across functional boundaries in the common interest. The Web provides what appears to be, and may actually become, a highly efficient "one-stop-shop" kind of arrangement. This could be especially helpful for "bureaucratically illiterate" citizens and their sponsors, who may conventionally have failed to access information and entitlements because they were spread across physically separate institutions such as justice, housing or childcare. Of course, it could also exacerbate the problems of those who find themselves experiencing access difficulties in any one area. In the meta sense, this is a "market of markets". The e-government aspect is one of providing an intermediary function that combines or aggregates services that, while continuing to be performed by separated organisations, offer the citizen-consumer the appearance of a single integrated function.

\subsection{Public Sector Markets and the eDebate}

The public sector market is hugely diverse in terms of population, structure, demand and activity. In as much as society can be regarded as a market for public sector services, citizens can be understood as consumers of the outputs of political and public sector organisations and processes. Citizen-consumers take the form of students, patients, residents, motorists etc. Their unifying characteristic, however, is that they are citizens. As citizens, people define themselves in terms of identity, rights and duties. Citizens, however, may expect to be treated as customers, but may not care to be referred to as such. Citizenship is also an egalitarian notion, suggesting equality of treatment by representatives of the state regardless of rank or fortune. This idea is reinforced by the fact that public goods are free at the point of delivery, and the link between use and taxation is long and tenuous. Further, people play multiple roles as public service consumers, being at the same time funders, users and assessors.

Citizens can usually find redress for grievances i.e. dissatisfaction with services, through constitutional, political and legal remedies. Consumers, on the other hand, typically engage in complaining behaviour. Citizens owe loyalty but consumers can more easily exit the relationship (Hirschman 1970). Much of the change in the 
market characteristics for public services revolves around the attempts by governments tutored by public choice models to educate citizens to act like consumers. Thus, for example, the increasing use of citizens' charters in the public services is aimed at facilitating complaint and comprehension for service users, i.e. customers (Millar and Peroni 1992). The authors of such charters expect better public services to result from a market of customers than one of citizens.

Better informed citizens, acting as confident consumers, make for a better democracy. The establishment of e-government should reduce the efforts of complaint, thereby enabling better quality feedback from the marketplace and more responsive service providers. Accepting the citizen as a consumer allows for development of the marketplace analogy. Getting services to the market is the function of channels, a conceptualisation that is important in understanding the potential for e-government.

Three main channel effects of ICT developments may be identified. First, disintermediation occurs where the channel is shortened because the customer accesses the producer directly. In the government situation, this could be where the citizen no longer needs to go through an agency of some kind. The contact is direct, without need for intercession. Cultural norms, as well as established practices and structures, will influence the appropriateness or otherwise of disintermediation. Second, the establishment of information intermediaries (infomediaries) (Hagel and Rayport 2000) is another development. In this case, the channel gets longer by the introduction of a new player, the function of which is to improve the information flows in one or both directions. Although the channels appears to have more members, and so become longer, if the infomediary cuts through complicated infoclutter, and actually adds value, it is a positive contribution. Third, the concept of metamediaries has been outlined above (Sawhney 1999). In this context it may approach a combination of political and public sector services accessed through a single point. The obvious advantages include the development of political and public sector arrangements more in keeping with the publics' perspectives than the providers'. These kinds of market or channel solutions are not mutually exclusive; all may exist in a complementary fashion.

\section{CONCLUSIONS}

Clearly, none of the advocates for e-government and e-democracy is ill intentioned towards democratic principles. They may feel some impatience at the idiosyncrasies of the current processes, and point optimistically to the potential for electronic access to information and channels of participation. The argument of this paper, however, is that these benefits, though real, are also fraught with danger for democracy. In Burke's terms, the e-democracy advocates are in danger of being deluded by the technical advances into neglecting the inherently conflictual nature of 
both government and democracy. However efficiently delivered, information about politics is never neutral; it is given to effect government outcomes. The distinctive characteristics of the political and public sector contexts must be addressed by the proponents of e-based solutions. There would be an arrogance and ignorance on the part of those who would seek to import directly technology-based solutions from the commercial world into the relations between the state, the public institutions and the citizenry. Consideration in the first instance of the peculiar aspects of public services, organisations and marketplaces would bring a contextual sensitivity to the project, thereby improving subsequent design and application. Our conclusion is that more attention should be paid to the mechanisms of representative democracy so that they can be incorporated into e-systems rather than clash with them.

\section{REFERENCES}

Butler, P. and Collins, C. (1995), "Marketing Public Services: Concepts and Characteristics", Journal of Marketing Management, Vol. 11, N0. 1-3, pp83-96.

Ford, D. (Ed.) (1990), Understanding Business Markets: Interactions, Relationships and Networks, Academic Press, London.

Hagel, J. and J.F. Rayport (2000), “The New Infomediaries”, The McKinsey Quarterly, No. 3. Hirschman, A.O. (1970), Exit, Voice and Loyalty: Response to Decline in Firms, Organisations and States, Mass, Harvard University Press.

Kaplan, S. and M. Sawhney (2000), "E-Hubs: The New B2B Marketplaces”, Harvard Business Review, May-June, pp.97-103.

Lane, J.E. (1993), The Public Sector: Concepts, Modules and Approaches, London, Sage. Millar, S and F. Peroni (1992), "Social Politics and the Citizens Charter", in Social Policy Review, Manning, N. and R. Page (Eds) Vol. 4.

Morris, D (2000), Vote.com, Los Angeles, Renaissance Books.

Page, B.I. (1983), Who Gets what From Government, Los Angeles, UC Press.

Sawhney, M. (1999), "Making New Markets", Business 2.0, May, pp. 16-21.

Webster, F.F (1992), "The Changing Role of Marketing in the Corporation", Journal of Marketing, Vol. 56, pp. 1-17.

Wise, R. and D. Morrisson (2000), "Beyond the Exchange: The Future of B2B", Harvard Business Review, November-December, pp.86-96. 